\begin{tabular}{|l|l|}
\hline Conceptos clave para la formación & $\begin{array}{l}\text { Sergio Héctor Barreiro Torres (coordinador) } \\
\text { Julio A. Muñoz Marañón } \\
\text { René Hernández de la Rosa }\end{array}$ \\
Diseño para la producción \\
p. [137]-170 \\
En: \\
Gutiérenador Industrial \\
Conceptos clave para la formación del Diseñador \\
Industrial. Ciudad de México: Universidad Autón oma \\
Metropolitana, Unidad Azcapotzalco, 2012. 312 páginas. \\
Fuente: ISBN 978-607-477-626-3 \\
Relación: \\
$\frac{\text { http://hdl.handle.net/11191/7663 }}{\text { https://doi.org/10.24275/uama.352.7663 }}$
\end{tabular}

\begin{tabular}{|c|c|c|}
\hline 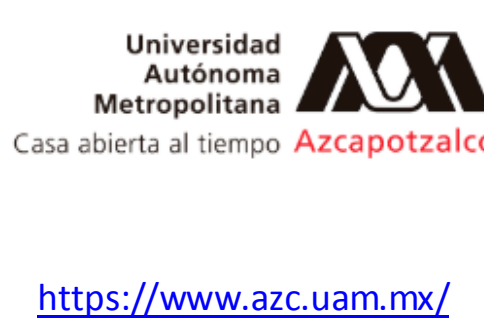 & $\begin{array}{l}\text { División de Ciencias y Artes para } \\
\text { el Diseño } \\
\text { https://www.cyad.online/uam/ }\end{array}$ & $\begin{array}{l}\text { Departamento de Evaluación del Diseño en el } \\
\text { Tiempo } \\
\text { http://evaluacion.azc.uam.mx/ }\end{array}$ \\
\hline (c) $(1) \Theta$ & \multicolumn{2}{|c|}{$\begin{array}{c}\text { Excepto si se señala otra cosa, la licencia del ítem se describe como } \\
\text { Atribución-NoComercial-Sin Derivadas } \\
\text { https://creativecommons.org/licenses/by-nc-nd/4.0/ }\end{array}$} \\
\hline
\end{tabular}

D.R. (C) 2012. Universidad Autónoma Metropolitana. Unidad Azcapotzalco (UAM Azcapotzalco). Se
autoriza copiar y redistribuir el material en cualquier medio o formato, siempre y cuando se den los
créditos de manera adecuada, no puede hacer uso del material con propósitos comerciales, si
remezcla, transforma o crea a partir del material, no podrá distribuir el material modificado. Para
cualquier otro uso, se requiere autorización expresa de la UAM Azcapotzalco.


DOI: 10.24275/uama.7048.7674

- Capacidad de producción

- Ciclo de vida del producto

- Componente

- Desarrollo de productos

- Dimensiones generales

- Especificaciones

- Estándares de calidad

- Estandarización

- Manufactura

- Materiales

- Partes

- Planos de producción

- Procesos de fabricación

- Producto industrializado

- Sistema normalizado

de representación

e interpretación

- Tolerancias geométricas y dimensionales 
DOI: 10.24275/uama.7048.7674

DESARROLLO DE CONCEPTOS POR:

DI. Sergio Héctor Barreiro Torres (Coordinador)

MTRO. Julio A. Muñoz Marañón

Profesores-investigadores del Departamento

de Evaluación del Diseño en el Tiempo,

División CyAD, UAM/Azc.

DI. René Hernández de la Rosa

Jefe de Desarrollo de Nuevos Productos

en Electrónica (Clarion, S.A. de C.V.) 


\section{Diseño para \\ la producción}

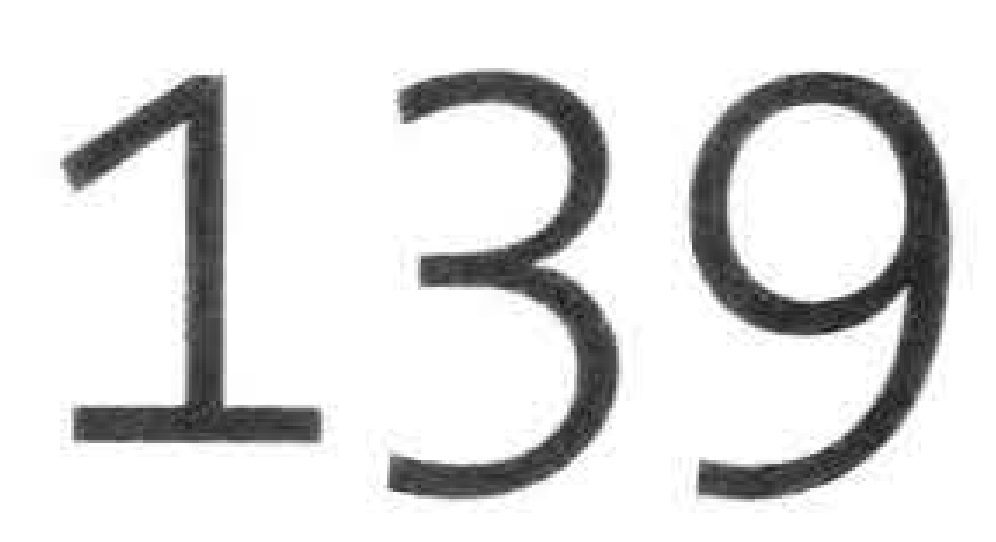

El mundo está cambiando a cada instante a una velocidad inconcebible y una parte importante de esta transformación, que no de evolución, tiene una intima relación con la actividad denominada hoy en día de manera genérica como diseño; un fenómeno de nuestro tiempo que desde el punto de vista filosófico es representativo de una estética degradada, de una estética del espectáculo o de una estética de las mercancías, que en general vivimos o hemos vivido, en la era moderna y posmoderna, a lo largo del siglo pasado e inicio del actual.

De manera independiente a la especialidad a la cual se refiera, pues existen múltiples acepciones de esta disciplina del diseño (gráfico, arquitectónico, de interiores, de envase y embalaje, de modas, industrial), éstas y todas las distintas especialidades o campos de aplicación del diseño comprenden principios, objetivos, mecánicas de análisis y de sintesis, de desarrollo, creativas, de producción, de resultados y hasta de insumos que son comunes, empezando por la propia naturaleza de este acto, que es considerado dentro de los más específicamente humanos, por lo que ha alcanzado una categoria estética según la propia filosofía, ya que el efecto, manifestado en su resultado o producto, es o debería ser representativo de nuestra cultura, de nuestra sociedad, de nuestra "civilización", además de que para su realización, para su práctica, se apoya en otro relevante factor humano o racional, constituido por las actividades de planeación, que implican o presuponen una intención predeterminada que incumbe no solamente a la funcionalidad o a la utilidad de un producto, sino también a su impacto económico, social, tecnológico y, hoy en día, a la imprescindible consideración del impacto ambiental, de manera que la apariencia final de todo producto diseñado debería ser "racionalmente" predeterminada y definida 
por las variables de naturaleza contextual, que debe como único sustento pertinente ser la base para dar origen o configurar el producto diseñado. Este acto de diseño, que comprende desde la concepción a la creación y a la reproducción de una gran variedad de productos, resulta ciertamente complejo, dada su naturaleza holística, sin embargo, a diferencia del concepto que vierte André Ricard en su texto Diseño ¿porqué?, sobre la evolución natural comenta: "Es notable la similitud que vamos observando entre el proceso evolutivo natural de lo biológico y aquel que conduce la evolución de lo artificial" (Ricard, 1983:22).

Esta paulatina pero permanente evolución natural sigue una pauta que no afecta, sino por el contrario, enriquece, fortalece, y beneficia integralmente nuestro medio ambiente natural, el cual se ve directamente afectado pero de forma negativa por la "evolución de lo artificial" de naturaleza humana, creada por el ser humano, por lo que cabe plantear un cuestionamiento inicial sobre la validez, la pertinencia de este proceso y de la influencia de la participación del diseño para esta transformación de la proliferación irracional del entorno artificial, puramente de mercancías, a un verdadero proceso de evolución de lo artificial, lo que también nos indica que esta es la razón por la que resulta cuestionable identificar esta disciplina como la estética de nuestros tiempos, ya que hoy en día se trata solamente de una estética degradada, de una estética del espectáculo, o de una estética de las mercancías, cuyo valor es puramente crematístico y que su justificación es meramente mercantilista, sustentada por la comunicación de masas y por el marketing, careciendo de un fundamento racional, cultural, social o de cualquier otro tipo, como se ha venido dando hasta el inicio del presente siglo XXI.

Cabe considerar detenidamente la manera de abordar este tema de diseño para la producción, por lo que resulta relevante destacar la naturaleza del acto de diseñar, tratando de explicarlo desde la perspectiva de la experiencia profesional, para lo cual se puede iniciar comentando que por lo regular, al hablar de las distintas facetas o variables del diseño tendemos a visualizarlas de manera parcializada, por ejemplo, cuando se habla de las vertientes técnicas como son los materiales y los procesos de fabricación, no se relacionan con el resto de las variables, como son, los factores económicos, sociales o ambientales y ni que decir de los factores estético-simbólicos 
de los que son partícipes. Por ello, en esta primera parte se pretende asociar y exponer de forma explícita la gran diversidad de factores que intervienen en este proceso de diseño, en la configuración de los productos, relacionándolos con la producción, que es un factor que posee un carácter eminentemente técnico, asociándolo con factores de otra índole como lo serían el social, el económico, el ambiental, el cultural, el estético, etc, evidenciando así la complejidad de la naturaleza holística de esta disciplina.

La temática de este apartado "Diseño para la producción", parte de la reflexión sobre la categoría estética conferida al diseño en la actualidad, la cual se explica o se justifica solamente si este medio artificial creado por el hombre, es el resultado de una auténtica evolución material, que ha implicado para su realización la aplicación de cualidades que hasta hoy en día son consideradas netamente humanas, como ya se mencionó, además del pensamiento creativo y constructivo bajo una intencionalidad predeterminada, como una manifestación o expresión de nuestra sociedad, de nuestra civilización por lo que se deben de incluir sus finalidades, y se le debe dar un sentido todo esto desde una perspectiva holística. ${ }^{2}$

La importancia de la producción en el diseño ha sido un factor trascendental, por lo tanto, si revisamos de manera más detallada cómo influye o ha influido la forma en la que históricamente el hombre ha dado satisfacción a sus necesidades materiales, pues para lograrlo ha replanteado y transformado de manera radical no solamente el medio ambiente natural, sino su propia forma de vida, sus creencias, sus valores, su forma de sentir y de ser, su forma de relacionarse con su medio natural y social, con el mundo en general.

El trascendental fenómeno de la Revolución Industrial, del cual todavía hoy en día estamos analizando y evaluando con un mayor grado de detalle los trascendentales e irreversibles cambios a los que ha dado lugar; uno de los más importantes es el que tiene que ver con el concepto mismo de la tecnología, ya que está íntimamente relacionado con la producción, la nueva forma mecanizada de producción, que surge o se deriva de esta eclosión, de la evolución de la cultura humana, que tuvo lugar, como todo proceso histórico, no en una fecha precisa sino que fue gestándose entre el siglo XVIII y el XIX. La Revolución Industrial, fue una manifestación provocada por el conocimiento científico que hizo explotar, incendió el espíritu humano de una manera no-
1. Conviene recordar que la antigua utopía del diseño fue de naturaleza estética. Subyacente a la teoria alemana de la "Buena Forma", por ejemplo, además de una estética de la mercancía propuesta con relación al mercado y con vista al consumo masivo, habia también un ideal democrático (Anna Calvera, et al., De lo bello de las cosas, materiales para una estética del diseño, Barcelona: Gustavo Gili, p. 17). 
table, determinando cambios sustanciales e irreversibles de todo tipo, pero principalmente en lo económico, en lo social y en lo ecológico.

Surge durante el desarrollo de la máquina de vapor que patentó James Watt en el año de 1775, para este año ya existían o ya habían sido desarrollados otros medios para sustituir y multiplicar la fuerza humana, como la rueda hidráulica y el molino de viento, éstos y otros "inventos" y el conocimiento generado por los mismos sirvieron de base para este nuevo desarrollo. El resultado obtenido por James Watt, fue la culminación de toda una serie de antecedentes teóricos, técnicos, prácticos y experimentales, que a su vez dieron lugar a la máquina de vapor como un producto final, como producto terminado, que es calificado por todos como invento, aunque yo lo calificaría como desarrollo, pues tuvo una serie de antecedentes que posibilitaron alcanzar este resultado, lo fundamentaron, aplicando principios tanto teóricos como técnicos y prácticos para el planteamiento de las diversas soluciones, para la fabricación de prototipos, así como para la elaboración de la respectiva documentación, para alcanzar el resultado final.

Éste, en apariencia sencillo proceso, es el bosquejo del método o la forma por medio de la cual es posible crear o desarrollar la más completa tecnología, el proceso básico de prueba y error, de planteamiento de soluciones posibles, con sus respectivos cálculos, su detallada configuración y documentación, además de la construcción de prototipos para la comprobación de las hipótesis o soluciones viables, proceso en el que nos seguimos apoyando hasta la actualidad, la única diferencia que existe con el proceso del desarrollo tecnológico es el proceso de retroalimentación, que es o debería ser aplicable por lo menos en el campo del diseño industrial de manera sistemática, por medio del análisis de productos existentes, la revisión del estado del arte o al menos de las patentes relacionadas con los productos a diseñar, como una de las actividades iniciales para el desarrollo de cualquier proyecto.

Con esta explicación puntualizamos sobre una sencilla mecánica, pero que no se realiza, que se obvia pues parece evidente, ésta es una de las razones por la que no llegamos a resultados o los resultados a los que llegamos no alcanzan un contenido significativo.

Un aspecto sobresaliente que se obtuvo, como el subproducto de mayor trascendencia de la Revolución Industrial, que vemos claramente represen- 
tado como consecuencia directa de la misma, fue la potencialización que se obtuvo en la capacidad de producción del ser humano y aunque éste fue solamente uno de los resultados, repercutió también en la economía, la sociología, la política, la filosofía, las ciencias en general, en la vida del hombre sobre la tierra y en la propia vida de nuestro planeta.

Otro de los factores que no son claramente visualizados como resultado de la Revolución Industrial, pero son elementos que también potencializaron al hombre a aumentar su capacidad de producción, pues a diferencia del artesano que produce manualmente o manufactura excedentes previamente concebidos, no sólo para satisfacer sus propias necesidades, sino para satisfacer las necesidades ajenas, fue que el hombre al empezar a producir apoyado por medios mecanizados, incrementa dicha capacidad de producción y, como consecuencia, incrementa su capacidad de ganancia material, por medio de lo cual se ve en la posibilidad de acumular riqueza.

Asimismo, existen otras implicaciones que son las que atañen de manera directa en la temática de diseño para la producción, pues esta forma mecanizada de producción trae otras consecuencias de gran importancia, que sustentan el explosivo desarrollo de la tecnología actual, es decir, la mecanización de la producción no sólo posibilita, sino determina la disociación del proceso productivo, lo que quiere decir que hace posible dividir el proceso de producción de un producto completo en partes, dando lugar a lo que podríamos considerar como una 2da. "Revolución Industrial" creada o concebida por el ser humano: la estandarización, ésta no sólo nos lleva a potencializar, más aún la capacidad de producción, sino da la pauta a la aplicación de normas tanto para los productos como para los procesos, dicha mecanización además nos brinda la capacidad de reproducir una pieza que podemos repetir de manera idéntica un número indefinido de veces, siguiendo las características definidas dentro de las especificaciones propias de cada producto y cada proceso, en cada una de las partes producidas. Las especificaciones representan la última versión o alternativa más desarrollada del producto en cuestión, por lo que requiere de un sistema de control, éstas no incluyen únicamente los materiales y sus respectivos procesos de fabricación, comprenden, además, desde las dimensiones con sus respectivas tolerancias, hasta los acabados que deben aparecer determinados 0 especificados en los planos de producción, como parte importante o más 
bien básica, para aplicar y aprovechar estos nuevos medios de producción, los que deben de ser considerados como el fundamento para el desarrollo tecnológico, pues contienen toda la información a último nivel de desarrollo, requerida para la reproducción actualizada de cualquier producto, que hoy en día por medio de su respectiva documentación puede realizarse 0 fabricarse en cualquier parte del mundo, obteniendo exactamente el mismo resultado, con lo que vemos reflejado el fenómeno de la globalización.

El fundamento para alcanzar el Desarrollo Tecnológico se encuentra en los elementos antes mencionados, son los principios para lograrlo, a los que hay que agregar los métodos e instrucciones de trabajo contenidos en los $\mathrm{Ma}$ nuales de Calidad con los que cada empresa debería de contar. Toda esta información integra el conocido "Paquete Tecnológico" y representa ni más ni menos el denominado Know how, actualmente el producto más costoso para nuestras empresas y nuestros países, ya que en vez de invertir en desarrollarlo internamente, ya sea por medio de proyectos y/o productos promovidos por empresarios o autoridades de manera endógena, optan por comprarlos ya desarrollados y, por lo general, corresponde a proyectos y/o productos desarrollados y probados en otros países, con base en otras realidades, en otro contexto, que implica que para venderlos es necesario promocionarlos aunque sean diseñados y fabricados en y para otros ámbitos, para responder a otras necesidades y bajo una finalidad última de naturaleza mercantil, crematística, para asegurar el éxito de su inversión, degradando la categoría estética del diseño y limitando la participación de nuestra profesión en el desarrollo tecnológico endógeno y, sobre todo, dando lugar a que la riqueza proveniente del valor agregado, que es posible crear a través de la participación del diseño propio, sirva para apoyar una mejor distribución de la renta dentro del país, que auspicie una verdadera democratización económica y de recursos materiales, esta situación es aprovechada en otras latitudes, en otros países, pues la riqueza que es posible crear, emigra.

Por todo lo anterior, es necesario hacer hincapié que uno de los fundamentos para el Desarrollo Tecnológico es la documentación adecuada de cada proyecto de diseño, a lo largo de todo su proceso; la parte correspondiente a la realización de los planos debe responder a un sistema normalizado de representación e interpretación que a su vez corresponde a un sistema reconocido por algún organismo calificado para ello. En México 
existe la NOM, que corresponde a la Dirección General de Normas de la Secretaría de Economía, sin embargo, en la práctica profesional existen muy diversas interpretaciones de la misma y hasta puede afirmarse que en las grandes empresas, generalmente transnacionales, son aplicadas normas propias que son desarrolladas internamente, por los grandes corporativos cabe mencionar que las diferencias entre estas normas y la mexicana no son significativas y son consistentes según el tipo de industria de la que se trate, por lo que a veces existen diferencias en los criterios de aplicación de algunos detalles como acotaciones, tolerancias, sistemas de medición, formatos, símbolos, tabla de cambios, sistemas de proyección, cuadro de referencias y control de cambios.

Entre los diversos tipos de planos requeridos para la reproducción de un producto dentro de los que se encuentran, entre otros, los denominados de presentación que corresponden a los planos de vistas generales, de cortes y detalles, los isométricos, los de despiece y los de producción que son de pieza por pieza.

Como mencionamos anteriormente los planos son la base para desarrollar cualquier producto ya que contienen o deben de contener la información requerida para que el producto en cuestión quede totalmente definido para poder reproducirlo, deben de estar documentados todos los detalles del mismo, para lo cual cada plano tiene una función predeterminada; así, los planos de vistas generales, con frecuencia, contienen la representación de las vistas más representativas del producto final, con sus respectivas dimensiones generales, alturas (eje Y), anchuras (eje X), profundidades (eje Z) y sirven para dar una idea general del producto completo.

Los planos de cortes y detalles son utilizados para la configuración geométrica de un producto, sobre todo, los que presentan una geometría irregular o complicada explican, asimismo, la configuración o disposición de los ensambles a través de los cortes, bajo el criterio de comunicar en forma lo más clara y precisa posible estos detalles para su fiel reproducción.

Los planos isométricos nos ayudan a visualizar el producto tridimensionalmente y hoy en día es muy usual agregar una vista isométrica en pequeña escala dentro del plano de vistas generales, para dar a entender con claridad la configuración del producto.

Los planos de despiece son de gran importancia ya que además de proporcionar la información básica de las configuración tridimensional del 
producto completo, muestra todas sus partes o componentes, en perspectiva isométrica, así como la disposición que guardan entre ellas, estos nos deben dar una idea clara de su configuración y presentar su cantidad, así como su respectiva denominación; también nos deben indicar o especificar tanto los materiales como los procesos de fabricación correspondientes de cada una de las partes del producto diseñado, aunque la mayoría de las veces por razones de espacio, estas especificaciones no pueden realizarse de manera detallada. Para lo cual resulta válido establecer estándares particulares.

Los planos de producción, en general, son planos pieza por pieza que contienen toda la geometría a detalle de cada una de las piezas que integran al producto, son de gran importancia, con relación al desarrollo de la tecnología, pues se trata de la información técnica básica generada en el desarrollo de un producto. Los planos de producción contienen información medular, no solamente de las dimensiones de las cada una de las partes sino la definición de las tolerancias relativas al material y al proceso por medio del cual el producto será fabricado, ya que estas difieren según sea el producto, su aplicación, su función, el propio material y los acabados, que son mencionados genéricamente en el despiece, pero en estos planos deben ser definidos de la manera más clara y específica. Por ejemplo, en el caso de un material prefabricado, de naturaleza metálica (un perfil de sección rectangular) debe especificarse sus dimensiones, composición química, el perfil de 2" x 1"de acero al carbón 1010, y los procesos de fabricación determinados que pueden ser de corte, troquelado, torneado, fresado, moldeado, etc, especificando las características a detalle del equipo correspondiente, por ejemplo, una máquina de inyección de 250 gramos de 350 toneladas de presión al cierre, especificar el equipo a utilizar y los requisitos del producto final, es indispensable aplicar los principios definidos dentro de las tolerancias geométricas y dimensionales, sistema normalizado que se aplica sobre todo en los productos configurados por varios componentes pues nos permiten definir de manera precisa la geometría de una pieza para alcanzar los ajustes necesarios para su mejor funcionamiento, también son requeridas en el caso de tratarse de piezas moldeadas, pues estas características son fundamentales para la fabricación de los moldes, para lo cual es recomendable utilizar los manuales de referencia.

Como hemos señalado, el proceso de documentación empieza con la información vertida en los planos del producto, a éste podremos calificar como 
un producto industrializado, una vez que haya pasado del proceso de diseño al de fabricación o producción por medios industriales de forma exitosa.

Actualmente es accesible y hasta recomendable la aplicación de la manufactura por control numérico, ya que esta tecnología cuenta con bases de datos de materiales y componentes normalizados, además de que simplifican la elaboración de los distintos tipos de planos, puesto que la información se obtiene del modelo tridimensional virtual, asimismo, esta información puede ser usada o aplicada como insumo para otros procesos posteriores al diseño como puede ser la fabricación de moldes o matrices cumpliendo las más estrictas especificaciones.

Una de las etapas finales por las que deben pasar hoy en día casi todos los productos, incluso los no industrializados, es la normalización. Existen infinidad de normas sobre el desempeño que los productos de todo tipo deben de cumplir, esta normalización nos da como resultado una serie de estándares de calidad, ${ }^{2}$ que aseguran el óptimo desempeño del producto en cuestión, así como sus procesos de fabricación. Sin embargo, el desempeño del producto, la mayoría de veces, no considera el ciclo de vida completo, es decir, desde su nacimiento hasta su destino final, dando lugar a la proliferación de deshechos o basura, que junto con otro tipo de deshechos altera el medio ambiente, por lo que urge incorporar dentro del proceso mismo de diseño, estrategias que contemplen la sustentabilidad previendo y considerando íntegramente el ciclo de vida del producto, ello significa extender el concepto actual, pues para definir el ciclo de vida del producto comprende desde su nacimiento hasta su desecho, como uno de los más importantes factores dentro de las nuevas propuestas y/o técnicas y/o métodos aplicados para que el desarrollo de productos alcance a cubrir amplia y auténticamente su significado, para que podamos hablar de una verdadera evolución material creada por el ser humano.

Sergio Héctor Barreiro Torres

\footnotetext{
2. Cabe mencionar que dentro de los actuales estándares internacionales ya existe la norma ISO 14000 que contempla los aspectos e impactos ambientales referentes a la fase de produción, sin embargo no contempla el propio "ciclo de vida del producto" completo.
} 


\section{Capacidad de producción}

\section{Definición Diccionario RAE (DENOTACIÓN)}

Capacidad (Del lat. capač̆tas, -ätis). 1. f. Propiedad de una cosa de contener otras dentro de ciertos límites. Capacidad de una vasija, de un local. 2. f. Aptitud, talento, cualidad que dispone a alguien para el buen ejercicio de algo. 3. f. Fís. volumen (magnitud). 4. f. Fís. Cociente que resulta de dividir la carga de una de las armaduras de un condensador eléctrico por la diferencia de potencial existente entre ambas. Su unidad es el faradio. 5. f. desus. Oportunidad, lugar o medio para ejecutar algo.

Obrar. 1.f. Der. Aptitud para ejercer personalmente un derecho y el cumplimiento de una obligación.

Jurídica. 1.f. Der. Aptitud legal para ser sujeto de derechos y obligaciones.

Producción (Del lat. productĭo, -ōnis). 1. f. Acción de producir. 2. f. Cosa producida. 3. f. Acto o modo de producirse. 4. f. Suma de los productos del suelo o de la industria. V. coste de producción.

\section{DESARROLLO O CONSTRUCCIÓN DEL CONCEPTO}

La capacidad de producción o capacidad productiva es el máximo nivel de actividad que puede alcanzarse con una estructura productiva dada. El estudio de la capacidad es fundamental para la gestión empresarial pues permite analizar el grado de uso que se hace de cada uno de los recursos en la organización y asi tener oportunidad de optimizarlos.

Los incrementos y disminuciones de la capacidad productiva provienen de decisiones de inversión o desinversión (por ejemplo, la adquisición de una máquina adicional).

También puede definirse como cantidad máxima de producción en la nomenclatura, surtido y calidad previstos, que se pueden obtener por la entidad en un periodo con la plena utilización de los medios básicos productivos bajo condiciones óptimas de explotación.

La expresión "capacidad de producción" es un término compuesto en el cual el significado de "capacidad", tiene una variada serie de acepciones o sinónimos referentes al volumen, amplitud e inteligencia.

En cuanto al término "producción" su significado es más claro y directo, pues se refiere a la acción de producir, a la cosa producida o al acto o modo de producir y tiene términos afines como crear, construir, emitir, fábrica, taller, colmena, fecundidad, cosecha, mina, generador, interés, renta, fertilizante, abundancia, fructifero.

Este concepto es muy utilizado en el área de ingeniería y, específicamente, en la Ingeniería Industrial, ya que su connotación implica uno de los objetos de estudio de esta disciplina. Se aplica directamente a la cantidad de productos que es posible fabricar por unidad de tiempo; un claro ejemplo lo podemos ver en las líneas de producción continua de los más diversos productos incluyendo tanto los productos industriales como los artesanales.

Para el diseño la capacidad de producción resulta ser un factor muy importante a considerar en la etapa en la que se seleccionan y definen los materiales y sus tecnologías de transformación, ya que estas variables son 
esenciales para establecer el valor de estos factores de la producción, de los cuales depende el costo final que será asignado a los productos. Debido a su importancia se han desarrollado diversas técnicas o métodos para que el diseño considere estas variables, conocidas como "Diseño para la manufactura y ensamble" (DFM y DFA, por sus siglas en inglés). Este aspecto es uno de los factores estratégicos por los que es posible agregar valor a los productos diseñados, al definir los materiales y procesos adecuados se pueden tener ahorros significativos sobre todo en las líneas continuas de producción.

\section{USOS O ACEPCIONES (ACLARACIONES)}

La capacidad de producción es una referencia muy utilizada en las empresas con procesos de fabricación continua, donde existen líneas de producción, con mano de obra o automatizadas, es un recurso indispensable para poder calcular y establecer los costos de producción respectivos de cada línea. Los costos de producción son un elemento esencial para definir los costos directos de fabricación ya que junto con los costos indirectos son utilizados para poder integrar o calcular los costos de venta del producto.

\section{SiNÓNIMOS}

Rango de producción, volumen de producción.

\section{ANTÓNIMOS}

Paro, retraso de línea de producción, desperdicio, despilfarro.

\section{EJEMPLOS}

La capacidad de producción en una planta industrial se mide por la cantidad de productos que puede fabricar, haciendo un uso óptimo de todos los recursos existentes en un periodo determinado de tiempo, por ejemplo, en la industria automotriz su capacidad ha llegando a estándares de producción de un vehículo completo por minuto, para lograr este nivel de productividad han sido desarrolladas diversas herramientas que nos remiten hasta finales de 189o, cuando Fréderick W. Taylor innova, al estudiar y difundir el management científico del trabajo, cuyas consecuencias son la formalización del estudio de los tiempos y del establecimiento de estándares. Frank Gilbreth añade el desglose del trabajo en tiempos elementales, entonces aparecen los primeros conceptos de eliminación del despilfarro o desperdicio y los estudios del movimiento de los materiales.

En 1910 Henry Ford inventó la línea de montaje para el Ford T, producto estándar. Alfred P. Sloan mejora el sistema de Ford introduciendo en G.M.el concepto de diversidad en las líneas de montaje.

Después de la Segunda Guerra Mundial, Taiichi Ohno y Shigeo Shingeo crean para Toyota los conceptos de "Justo a tiempo" (Just in Time), Reducción del desperdicio (Waste Reduction), Sistema de jalar (Pull System), que añadidos a otras técnicas de puesta en flujo, crean el Toyota Production System (TPS). Desde entonces, el TPS no ha dejado de evolucionar y de mejorar.

En 1990, James Womack sintetiza éstos conceptos para crear el concepto de "Lean Manufacturing" o Manufactura Esbelta, el saber hacer 
japonés se difunde en occidente a medida que se observa la evidencia del éxito de las empresas que aplican estos principios y estas técnicas.

\section{Ciclo de vida del producto}

\section{Definición Diccionario RAE (DENOtACIÓn)}

Se refiere a la evolución de las ventas de un artículo durante el tiempo que permanece en el mercado. Los productos no generan un volumen máximo de ventas de inmediato después de introducirse en el mercado, ni mantienen su crecimiento indefinidamente.

Concepto o herramienta de la mercadotecnia o marketing.

Las condiciones bajo las que un producto se vende cambian a lo largo del tiempo; así, las ventas varian y las estrategias de precio, distribución, promoción... (variables del "marketing mix") deben ajustarse teniendo en cuenta el momento o fase del ciclo de vida en que se encuentra el producto: etapas, gestión, prolongación, evolución.

a) Etapas. Los productos siguen un ritmo de ventas variable con el tiempo, como el representado en la Figura 4.1, y pasan por cuatro fases: introducción, crecimiento, madurez y declive.

La fase de introducción ocurre justo después del momento en que un nuevo producto se introduce en el mercado. Las ventas están a niveles bajos porque todavía no hay una amplia aceptación del producto. La disponibilidad del producto (para el comprador) es limitada. La competencia es limitada o nula. Si el mercado

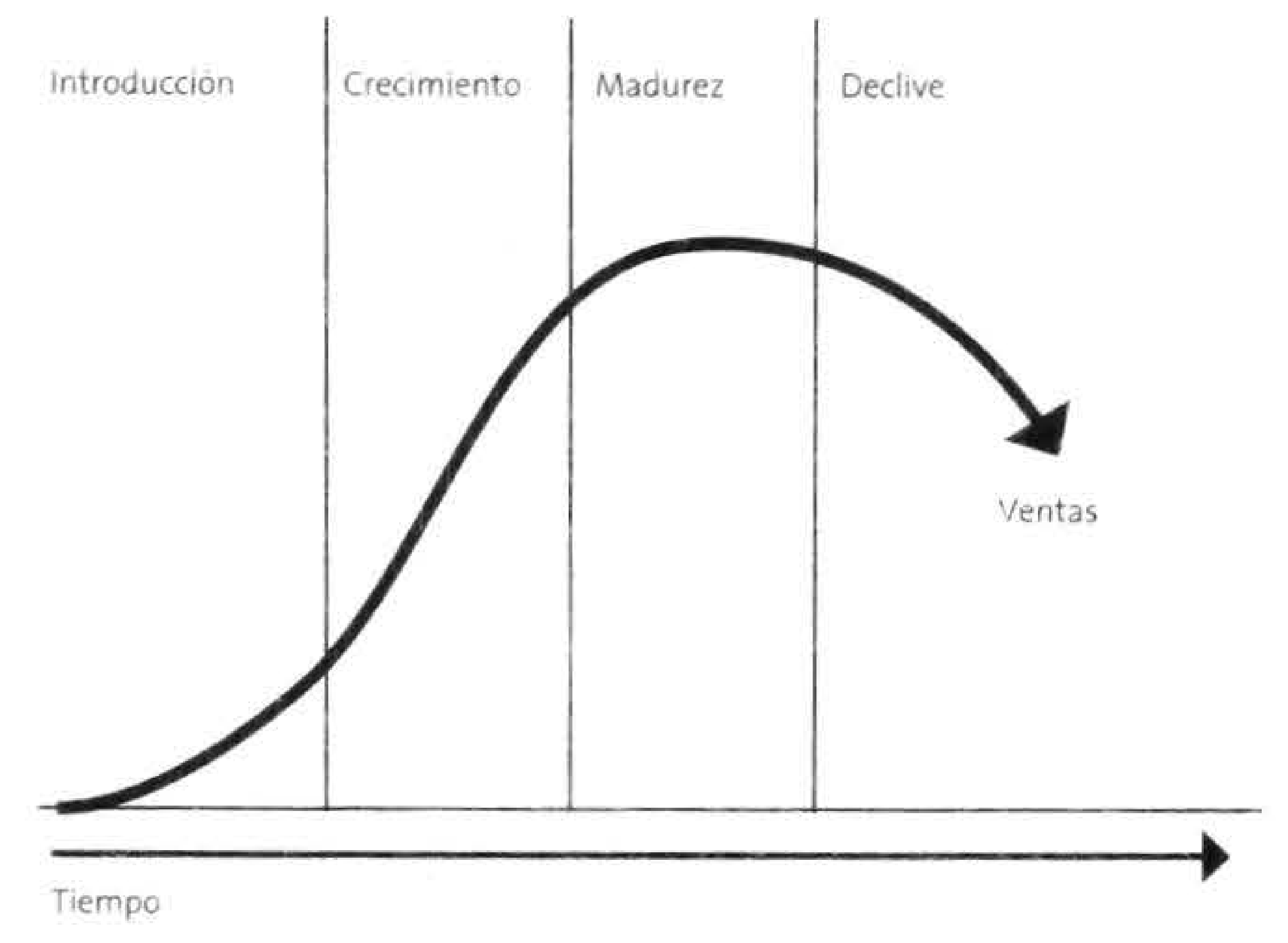

Figura 4.1. Ciclo de vida del producto.

acepta el producto (etapa de crecimiento), las ventas aumentan rápidamente. La planificación de la distribución física es difícil en esta fase (también llamada aceptación); sin embargo, la disponibilidad del producto se extiende rápidamente por toda la geografía, al acrecentarse el interés del comprador en el producto. Los beneficios aumentan porque el producto lo conocen los clientes. La anterior fase puede ser bastante corta, seguida de un periodo más largo llamado de madurez. El incremento de las ventas es lento o se ha estabilizado en un punto (los niveles máximo de ventas); entonces, ya es considerado un producto establecido en el mercado, por lo tanto, se puede decir que es un producto viejo. En este momento, se alcanza la mayor rentabilidad y se puede prolongar más tiempo con diferentes técnicas de marketing. Llega un momento en que las ventas decaen (declive o decadencia), para la mayoría de los productos por cambios en la tecnología, la competencia, o la pérdida de interés por parte del cliente. Con frecuencia los precios bajan y 
los beneficios se reducen. El CVP tiene su fundamento teórico o razón de ser en la "teoría de difusión de innovaciones".

b) Gestión. El ciclo de vida no es exactamente igual para todos los productos. Mientras que algunos tienen un lanzamiento durante un corto periodo, la mayoría de los productos de consumo se mantiene en la etapa de madurez durante años (por ejemplo, la leche). Las personas de marketing deben conocer la fase del ciclo en que se encuentran los productos para poder ajustar las políticas y estrategias del marketing mix a esa fase, ya que las estrategias van cambiando a medida que el producto pasa de una fase a otra.

La publicidad, por ejemplo, debe ser informativa en la etapa de introducción, persuasiva en las etapas de crecimiento y madurez, y orientada a mantener el recuerdo en la etapa de declive.

Los presupuestos para promoción tienden a ser mayores en las primeras etapas y van decayendo en las de madurez y declive.

El precio suele ser elevado en las fases de introducción y crecimiento, pero en la madurez el precio debe ser competitivo para mantenerse en el mercado.

La distribución es baja en la fase de introducción; más amplia en las fases de crecimiento y madurez, para volver disminuir en el declive.

c) Prolongación. Las compañías se esfuerzan por alargar la vida del producto todo lo posible, debido a que es mucho más barato mantener un producto en el mercado que retirarlo y lanzar otro nuevo. Los responsables de marketing han diseñado diferentes técnicas para evitar o retrasar la etapa de declive del producto. Existen tres patrones de prolongación del ciclo de vida del producto: 1. Madurez larga y estable. 2. Actualización. 3. Relanzamiento (Figura 4.2).
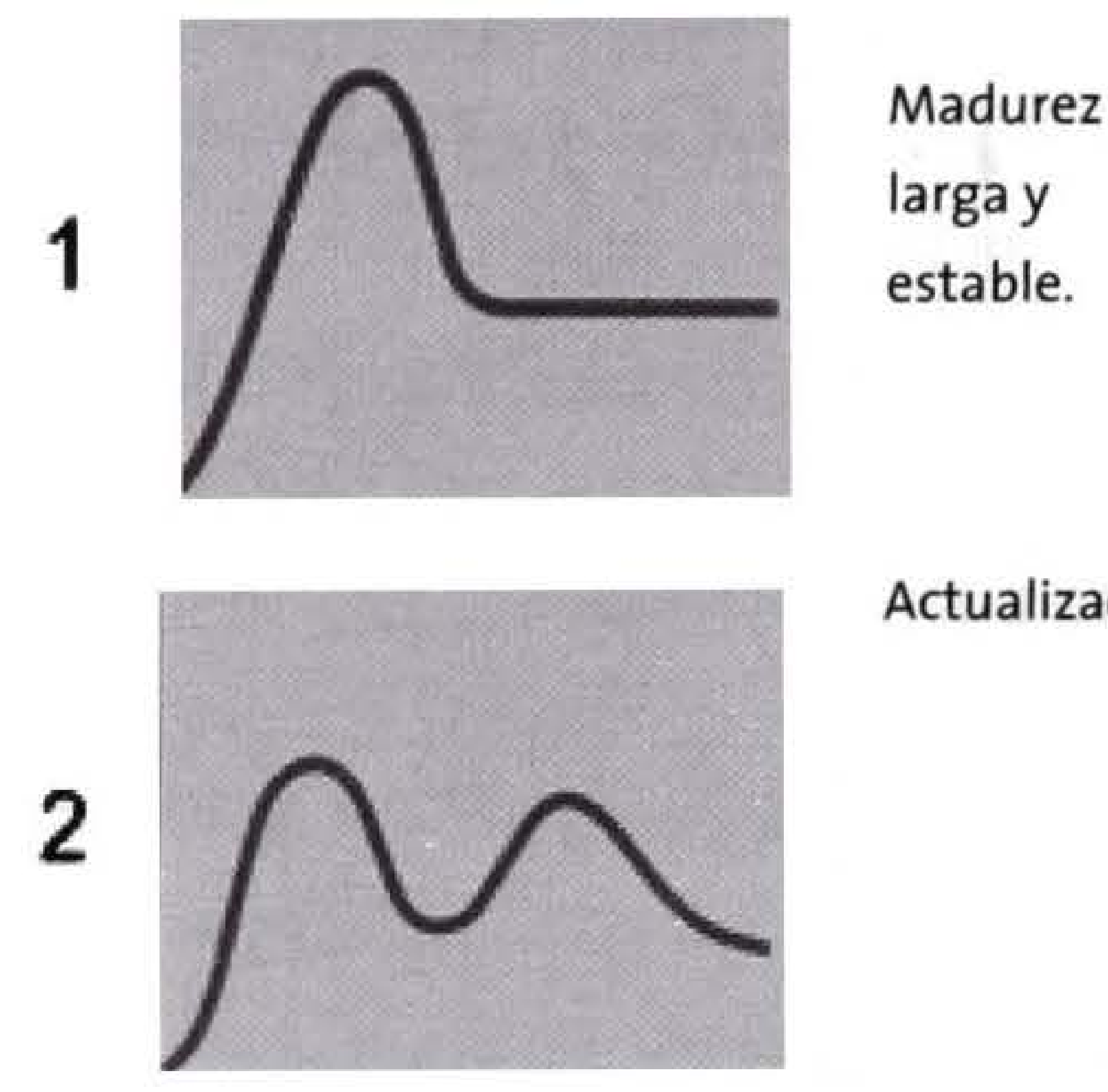

Actualización.

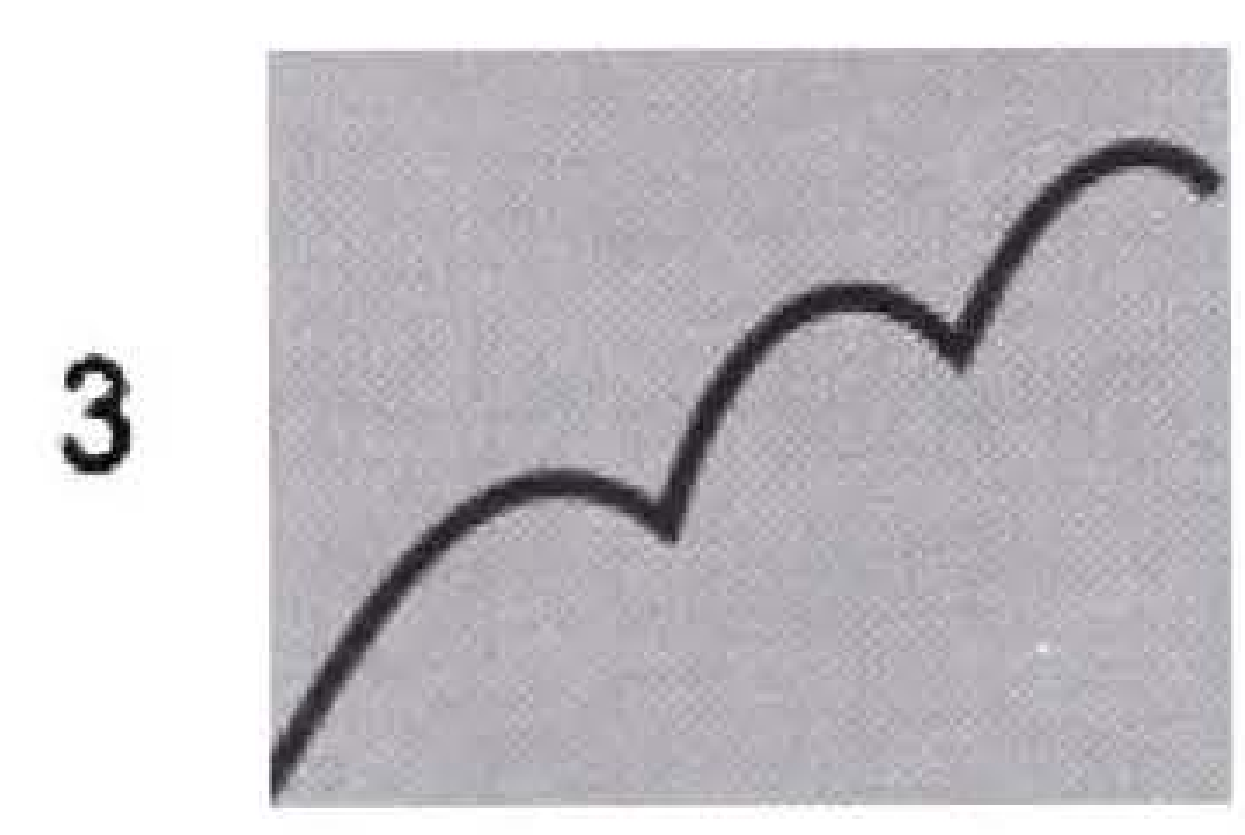

Relanzamiento.

Figura 4.2. Tipos de ciclo de vida del producto.

d) Evolución de mercado. Es un proceso paralelo al ciclo de vida del producto. A medida que la categoría de producto madura, la industria atraviesa momentos que se reflejan en las etapas del ciclo de vida del producto:

- Cristalización de mercado. La demanda latente de una categoría de producto se activa con la introducción de un nuevo producto.

- Expansión de mercado. Entran nuevas compañías en el mercado y cada vez son más los consumidores que conocen la categoría de producto.

- Fragmentación de mercado. La industria se subdivide en nutridos grupos competitivos 
a medida que entran más compañias en el mercado.

- Consolidación de mercado. Las compañías empiezan a abandonar el mercado debido a la dura competencia, la caída de los precios y la caida de los beneficios.

- Terminación de mercado. Los consumidores dejan de pedir el producto y las empresas que lo producen dejan de tener ganancias por lo cual su producto ya no es rentable y tienen sólo dos opciones actualizar el producto o retirarlo del mercado.

\section{DESARROLLO O CONSTRUCCIÓN DEL CONCEPTO}

El término proviene de la mercadotecnia y se refiere básicamente al periodo de tiempo comprendido desde la introducción de un nuevo producto al mercado, hasta su decadencia.

En cuanto al vocablo "Producto" se refiere a la cosa producida, el caudal que se saca de una cosa que se vende o que reditúa, cantidad que resulta de la multiplicación.

En su evolución el diseño adopta inicialmente el significado usado en la mercadotecnia, hoy en día ha desarrollado una visión más amplia de este ciclo de vida ya que se ha adquirido una visión responsable y racional al respecto, de categoría estética ya que se ha propugnado por ampliar este ciclo, abarcando no solamente el tiempo comprendido entre la introducción y la salida del producto del mercado, actualmente ya se está desarrollando la conciencia para que el ciclo de vida de todo producto sea considerado bajo un criterio más estricto en términos de sustentabilidad que abarque desde la concepción, hasta el destino final del producto, buscando procesos o ciclos semejantes a los de los productos naturales.

En cuanto a "Producto", se debe de entender este término como el resultado final del diseño, como aquel objeto mediante el cual se logra satisfacer una serie de necesidades humanas, no solamente funcionales u objetivas, sino de naturaleza significativa o subjetiva, de todo tipo, de manera que un objeto (producto) debe mostrarse a sí mismo y auto explicarse sin ambigüedad, pero además satisfacer necesidades de otra naturaleza "que permitan que el sujeto establezca un sentido para sí mismo, que no es el sentido del mundo-verdad de los metafísicos, ni tampoco el mundo funcional de los pragmáticos".

\section{USOS O ACEPCIONES (ACLARACIONES)}

El ciclo de vida del modelo de automóvil nuevo se calcula a 5 años.

El ciclo de vida de los productos de informática se ha reducido debido a la competitividad de los corporativos líderes a nivel mundial.

Una medida enfocada para cuidar el medio ambiente sería la de ampliar el ciclo de vida de los productos, tomando en consideración la posibilidad de su total reciclaje.

\section{SINÓNIMOS}

Periodo de existencia del producto, época de supervivencia del producto, tiempo de duración del producto.

\section{ANTÓNIMOS}

Producto caduco, inexistencia de productos. 


\section{EJEMPLOS}

Una de las especialidades más dinámicas dentro del diseño es el Diseño de Modas, ya que el ciclo de vida de los distintos modelos o productos cambia de manera casi constante y es impredecible, los dicta la demanda de un mercado sustentado en la comunicación de masas.

\section{Componente}

\section{Definición Diccionario RaE (DENOtación)}

Componente: que compone, o forma parte de una composición. La palabra componente puede hacer referencia a: componente electrónico; dispositivo que forma parte de un circuito electrónico. Video por componentes; señal de video que ha sido dividida en dos o más componentes (no confundir con video compuesto). Análisis de componentes principales; técnica utilizada para reducir la dimensionalidad de un conjunto de datos. Componentes de un vector. Componente de software.

\section{DESARROLLO O CONSTRUCCIÓN DEL CONCEPTO}

Para el diseñador es un término comúnmente aplicado para cada una de las partes o piezas que integran un producto, sin embargo resulta oportuno acotarlo. En primer lugar se puede referir a los productos que están integrados por una sola pieza, o parte y resulta válido denominarlo como de un solo componente, pues la definición del diccionario no hace alusión alguna a la cantidad, por lo que este término, en apariencia, puede ser usado indistintamente para designar productos integrados por una o varias partes, piezas o componentes. Por otro lado, también resulta conveniente comentar que en productos complejos que están integrados por una numerosa cantidad de componentes, se denominan como componentes a ciertos conjuntos que cumplen una función específica, o son del mismo material o poseen alguna característica común, como serían los componentes para el soporte de una estructura, o los componentes de plástico de un automóvil; la mayor parte de las veces los componentes integran diversos tipos de productos finales de mayor complejidad, integrados por conjuntos de componentes de distintos materiales, funciones, tamaños, geometrías, especificaciones, etc..., por ejemplo, una computadora, un teléfono, un automóvil.

\section{USOS O ACEPCIONES (ACLARACIONES)}

- Planos de los componentes de un diseño.

- Los componentes de acero de un automóvil están siendo sustituidos por componentes de materiales plásticos.

- Las arenas semiconductoras son de los materiales más comunes para la fabricación de componentes electrónicos.

\section{SINÓNIMOS}

Partes, piezas.

\section{ANTÓNIMOS}

Conjunto, ensamble.

\section{EJEMPLOS}

Pedal, respaldo, pantalla. 


\section{Desarrollo de productos}

\section{Definición Diccionario RAE (DENOTACIÓN)}

El término desarrollo es utilizado con distintos significados por las disciplinas de las ciencias sociales:

Desarrollo humano, conclusión de capacidades que permitan a las instituciones y personas ser protagonistas de su bienestar. Índice de desarrollo humano, indicador estadístico del desarrollo humano por país.

Desarrollo social. Mejora de la calidad de vida y bienestar en la población.

Desarrollo rural. Desarrollo humano y económico en el medio rural.

Desarrollo local. Aprovechamiento de los recursos y potencialidades endógenos de una comunidad.

Desarrollo económico. Desarrollo de riqueza económica de países o regiones para el bienestar de sus habitantes.

Desarrollo sostenible. Fortalecimiento de capacidades en las poblaciones más vulnerables para la generación de oportunidades para crecer por ellas mismas, y dejar atrás la situación de pobreza en la que se encuentran.

Desarrollo tecnológico.

En biología, es un proceso por el que un organismo evoluciona desde su origen hasta alcanzar la condición de adulto.

En literatura, en un documento corresponde al cuerpo de éste.

En informática, se refiere al desarrollo de software y de videojuegos, es decir, la programación de los sistemas de cómputo.
En matemática, el término hace referencia al procedimiento realizado para la transformación de una expresión matemática en otra $u$ otras equivalentes y de igual validez conceptual.

En proyectos, se refiere al desarrollo de un proyecto, explica una teoría o idea, ampliándola y atravesando por todos sus pasos lógicos.

Producto puede referirse a: resultado de cualquier proceso, principalmente, la producción, la venta, la multiplicación (también se emplea para denominar a la operación en sí).

\section{DESARROLLO O CONSTRUCCIÓN DEL CONCEPTO}

Se refiere a una expresión compuesta por los términos de "desarrollo" y "productos", líneas atrás se hizo referencia al término producto, ahora precisaremos "desarrollo", éste se refiere a la acción o efecto de desarrollar o desarrollarse, por ejemplo: El desarrollo del cuerpo, sus sinónimos son: adelanto o crecimiento.

Cuando se aplica el término de desarrollo en el diseño se refiere al proceso por medio del cual se realizará, desde el planteamiento del problema hasta la conceptualización de su solución por medio de un producto, abarcando desde la producción, consumo y destino final de cualquier tipo de producto diseñado. Por naturaleza este desarrollo lleva implícitos todos los factores que intervienen en la integración del resultado o del producto final diseñado, el cual debe obedecer a una serie de necesidades o requerimientos de muy diversa naturaleza. La consistencia de este término de acuerdo a la definición establecida en el diccionario se refiere a la diferenciación armónica de sus componentes, 
funciones, apariencia, costo, del conjunto de características especificas que lo integran.

\section{USOS O ACEPCIONES (ACLARACIONES)}

El diseño industrial es una de las disciplinas que actualmente participan en el "Desarrollo de Productos", haciéndose responsable de los aspectos, no sólo técnicos y formales, sino también de los simbólicos, como parte de la propia estética de los mismos, desde una perspectiva de la estética filosófica.

Las técnicas del "desarrollo de productos" están siendo explotadas con un enfoque eminentemente mercantilista por distintas disciplinas y aplicadas en diversos tipos de empresas, incluyendo el Diseño Gráfico e Industrial y el resultado es la evidente devastación irracional de recursos, incluyendo la explotación a la que es sometido el propio ser humano, además de la proliferación de deshechos contaminantes de todo tipo.

\section{SiNÓNIMOS}

Adelanto, crecimiento, evolución.

\section{ANTÓNIMOS}

Retraso, decadencia, retroceso.

\section{EJEMPLOS}

El proceso de "desarrollo de productos" en la industria automotriz hace aproximadamente 20 años se llevaba a cabo en periodos de tiempo de hasta de 2 años ó mas.

Actualmente aplicando las "ténicas de desarrollo de productos" y las herramientas de la informática, este proceso se ha reducido hasta seis meses.

Actualmente dentro de las técnicas de "desarrollo de productos" se debe determinar como uno de los primeros pasos, la revisión de la variable de la sustentabilidad de los productos a desarrollar, para que sea considerada como una constante.

\section{Dimensiones generales}

\section{Definición Diccionario RAE (DENOTACIÓN)}

Dimensión. Aplicada en la geometría para determinar la longitud, extensión o volumen de una línea, superficie o cuerpo. Extensión de un objeto en dirección determinada. En música significa la medida de los compases.

General. Tiene dos acepciones, la primera es un adjetivo que significa común y esencial a todos los individuos que forman un todo, o a muchos objetos, aunque sean de diferente naturaleza.

Dimensión (del latín di-, divergencia; metiri, medir; -ción, acción) es cada una de las magnitudes que conforman la existencia. En el universo hay tres dimensiones espaciales y una temporal.

Un cuadrado posee dos dimensiones. Ampliándolo con una nueva dimensión genera un cubo, que es tridimensional. Añadiendo al cubo una nueva (que no se ve) genera un hipercubo, que es de cuatro dimensiones. La Figura 4.3 en proyección, ya que tal objeto no existe en nuestro espacio.

El mundo físico en el que vivimos parece de cuatro dimensiones perceptibles. Tradicional- 

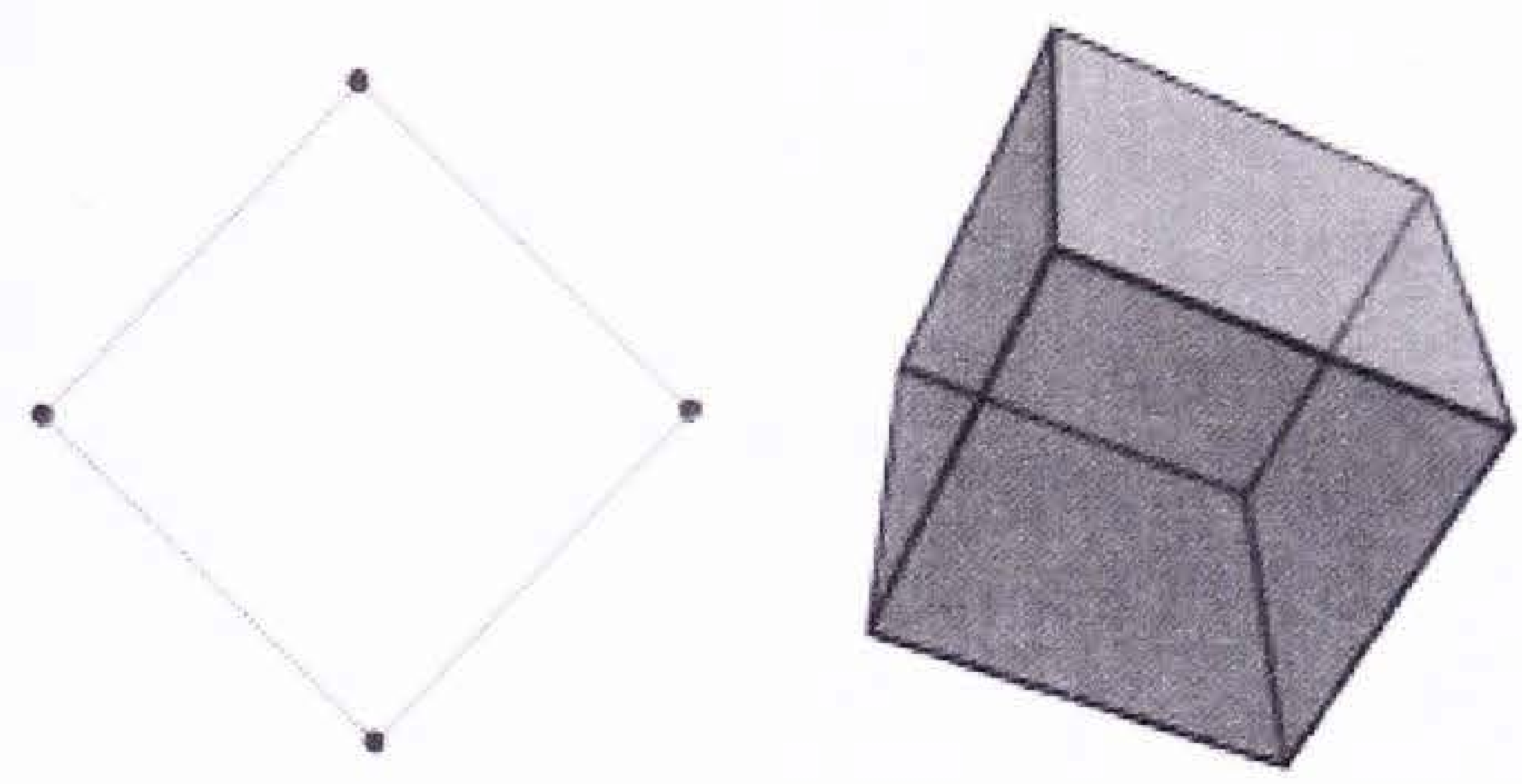

mente, se separa en tres dimensiones espaciales y una dimensión temporal (y en la mayoría de los casos es razonable y práctico). Podemos movernos hacia arriba o hacia abajo, hacia el norte o sur, este u oeste, y los movimientos en cualquier dirección pueden expresarse en términos de estos tres movimientos. Un movimiento hacia abajo es equivalente a uno hacia arriba de forma negativa. Un movimiento norte-oeste es simplemente una combinación de un movimiento hacia el norte y de un movimiento hacia el oeste.

El tiempo, a menudo, es la cuarta dimensión. Es diferente de las tres dimensiones espaciales ya que sólo hay uno, y el movimiento parece posible únicamente en una dirección. En el nivel macroscópico los procesos físicos no son simétricos con respecto al tiempo. Pero, a nivel subatómico (escala de Planck), casi todos los procesos físicos son simétricos respecto al tiempo (es decir, las ecuaciones utilizadas para describir estos procesos son las mismas independientemente de la dirección del tiempo), aunque esto no significa que las partículas subatómicas puedan regresar a lo largo del tiempo.

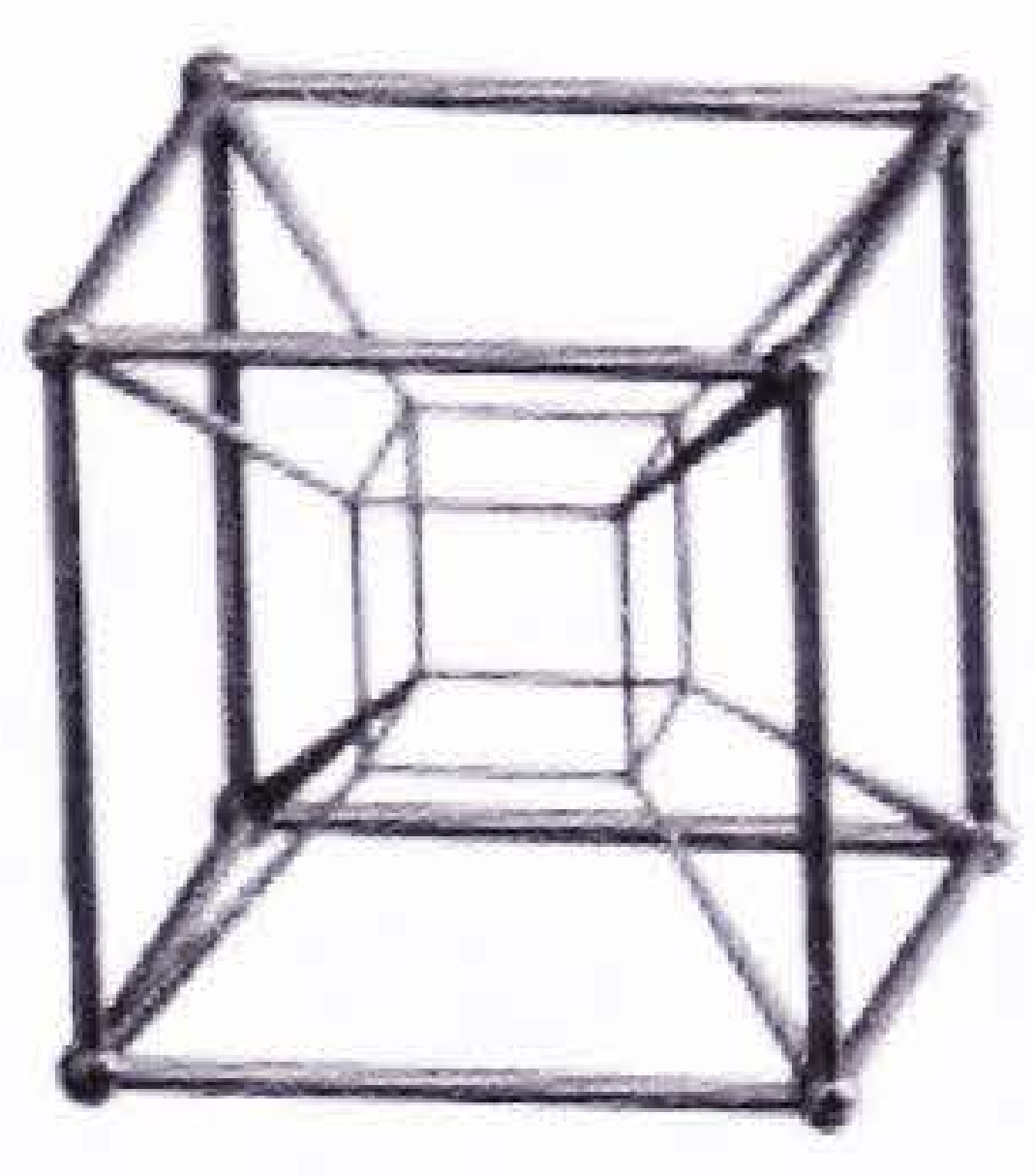

Figura 4.3. Dimensiones de un cubo.

La Teoria de las cuerdas conjetura que el espacio en que vivimos tiene muchas más dimensiones (10, 11 ó 26), pero que el universo medido a lo largo de estas dimensiones adicionales tienen tamaño subatómico. Estas ideas surgen en los años 20 en el contexto de las teorías de Kaluza-Klein (es.wikipedia.org/wiki/Diccionario_ de_la_lengua_española).

En las ciencias físicas y la ingeniería, del tamaño de una magnitud física es la expresión del tipo de unidades de medida en que esta cantidad se expresa. La dimensión de la velocidad, por ejemplo, resulta de dividir la longitud entre el tiempo. En el sistema SI, las dimensiones vienen dadas por siete magnitudes fundamentales relacionadas con las características físicas fundamentales.

Dimensiones matemáticas. En matemáticas, no existe una definición de dimensión que incluya de manera adecuada todas las situaciones. En consecuencia, los matemáticos han elaborado muchas definiciones de dimensión para los diferentes tipos de espacio. Todas, sin embargo, están en última instancia, basadas en el concepto de la dimensión del espacio euclídeo 
Figura 4.4. Dimensión de un espacio vectorial.

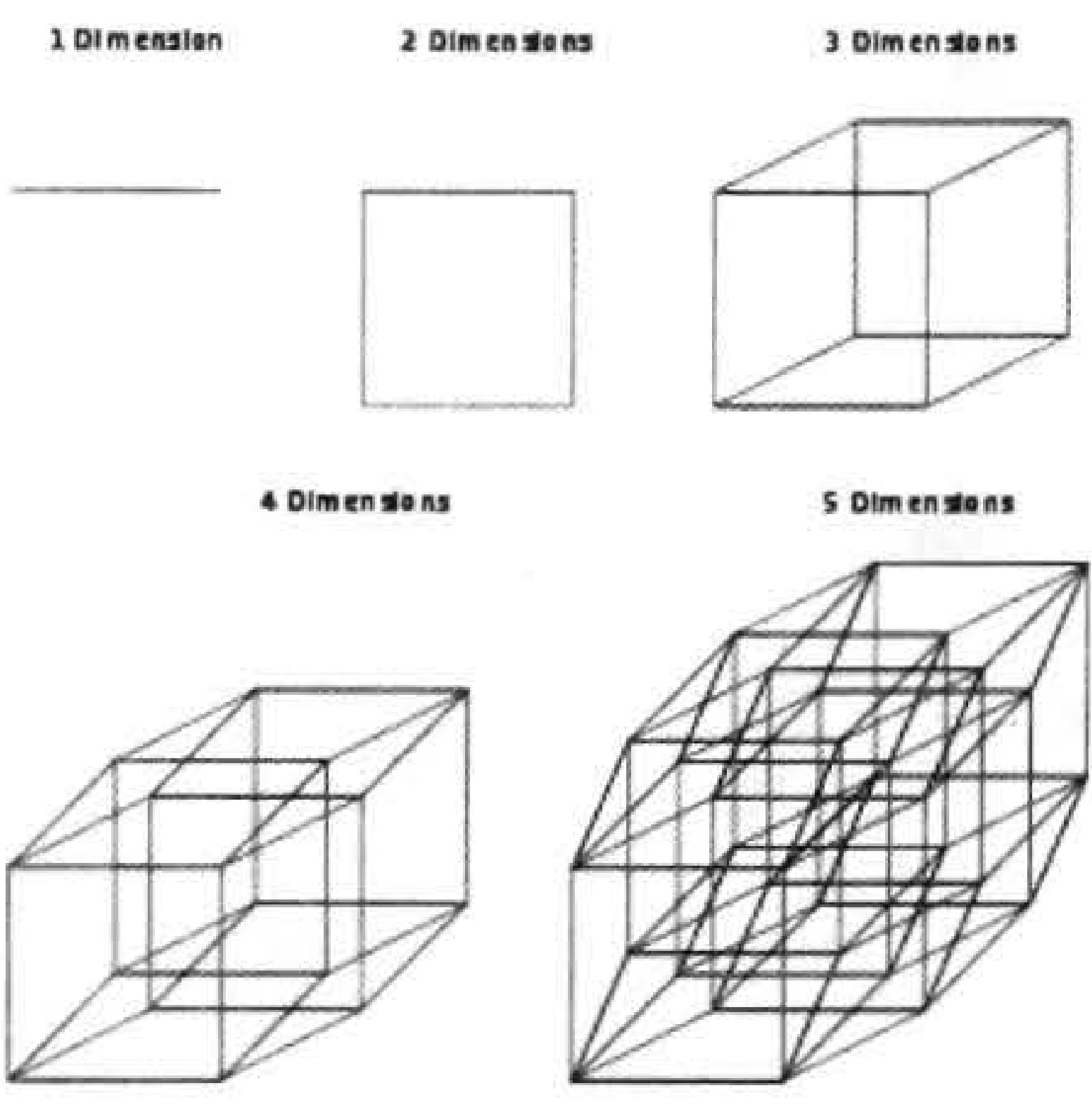

$n, E^{n}$. El punto $E^{\circ}$ es o-dimensional. La línea $E^{1}$ es 1-dimensional. El plano $E^{2}$ es 2-dimensional. En general, $E^{n}$ es n-dimensional (Figura 4.4).

Un espacio vectorial sobre un cuerpo que se dice que tiene dimensión si existe una base de cardinal n. En un espacio vectorial, todas las bases tienen el mismo cardinal, lo que hace de la dimensión el primer invariante del álgebra lineal. El espacio vectorial trivial $\{0\}$ tiene como dimensión o porque el conjunto vacío es su base: una combinación de cero vector da el vector nulo.

Al hablar intuitivamente, la dimensión de un espacio vectorial nos dice cuántos elementos necesitamos para poder expresar cualquier elemento del espacio en términos de las combinaciones lineales de los primeros, i.e., cuántos elementos del espacio necesitamos para poder expresar todos los elementos del espacio como sumas de múltiplos de estos elementos. Los espacios vectoriales de dimensión finita son muy comunes en muchas áreas de la ciencia, pero en matemáticas y física cuántica también aparecen casos importantes de espacios vectoriales de dimensión infinita (es.wikipedia.org/wiki/Diccionario_de_la_lengua_española).
La dimensión topológica es la que nos resulta más intuitiva y pragmática para comprender. Ésta establece la dimensión de un punto $=0$, la de una línea $=1$, la de una superficie $=2$, etc.

Más formalmente escrito, un objeto tiene dimensión topológica m cuando cualquier recubrimiento de ese objeto tiene como mínimo una dimensión topológica $=m+1$ (estableciendo previamente que el punto tiene dimensión topológica $=0$ ). Aún más formalmente: la definición para conjuntos con dimensión topológica o queda como sigue: se dice que un conjunto $\mathrm{F}$ tiene dimensión topológica o, $\mathrm{DT}(\mathrm{F})=0$, si y sólo si para todo $\mathrm{x}$ perteneciente a $\mathrm{F}$ y cualquier conjunto abierto $\mathrm{U}$ (para la topologia relativa de $\mathrm{F}$ ) que contenga a $x$, existe un abierto $V$ tal que $x$ pertenece a $V$ que está incluido en $U$ y la frontera de $V$ con la intersección a F es vacía (es.wikipedia.org/ wiki/Diccionario_de_la_lengua_española).

Dimensión fractal de Hausdorff-Besicovitch. Esta dimensión es comúnmente confundible con la entropía de Kolmogórov o la dimensión de Minkowski Bouligand. La dimensión de Hausdorff-Besicovitch se obtiene como un punto de inflexión del valor de la potencia 


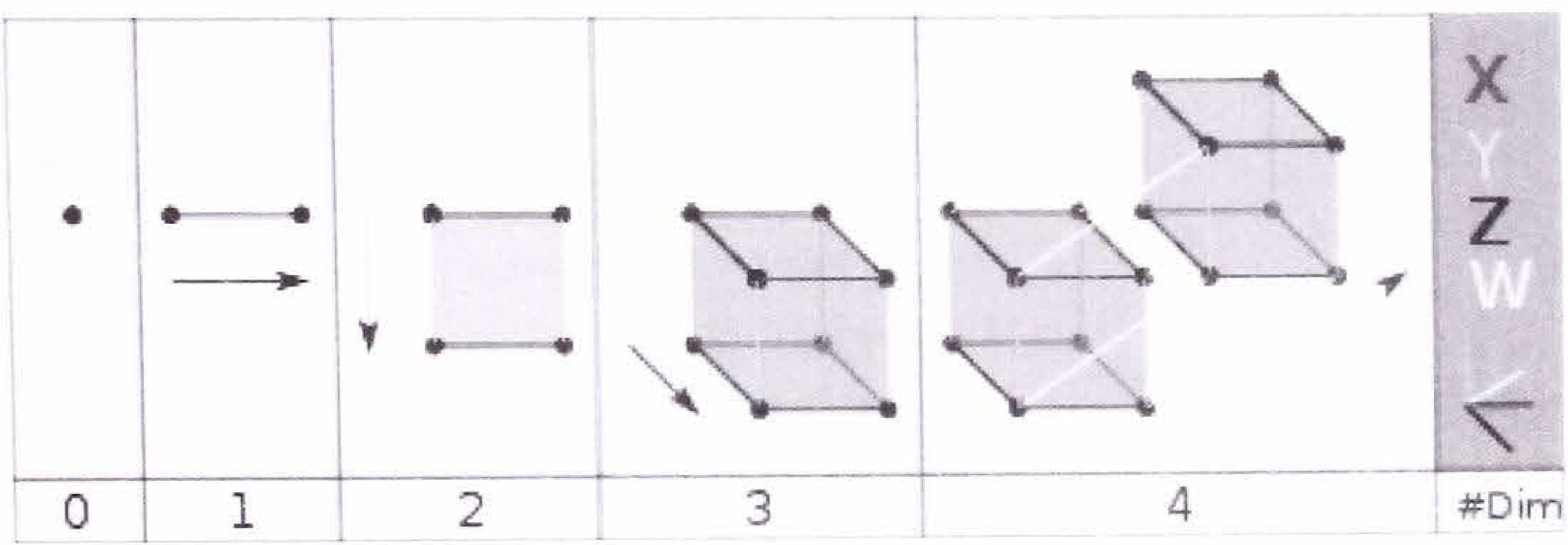

Figura 4.5.

Un diagrama que muestra las primeras cuatro dimensiones espaciales. elegida en la longitud de Hausdorff cuando esta pasa de ser infinita a ser nula. La longitud de Hausdorff es la suma del diámetro topológico elevado a una potencia "s" de un recubrimiento entero del objeto a partir de entornos o cubrimientos de diámetro delta o menor a éste del propio objeto (es.wikipedia.org/wiki/Diccionario_de_la_lengua_española).

La entropía de Kolmogórov, se denomina a una dimensión obtenida para facilidad de cálculos como el cociente logarítmico entre el número de homotecias internas encontradas en un objeto por transformación, y la inversa de la razón de esa homotecia. Es también llamada Box Counting Dimension y tiene una definición más intuitiva pero más larga al respecto.

Es de esta manera que los objetos euclidianos diferenciables se ven con una correspondencia en su valor dimensional topológica, de Box Counting y de H.B.

Esto no resulta con los fractales, que son definidos por Benoit Mandelbrot como objetos tales que su dimensión de Hausdorff - Besicovitch excede estrictamente su dimensión topológica.
Finalmente, sabemos que existen casos de fractales que no se apegan a esta definición; una de esas es la curva del Diablo, la cual es un fractal derivado del conjunto de Cantor.

En ciencia ficción, a veces se usa el término "dimensión" como sinónimo de universo paralelo; aunque la palabra este relacionada no son sinónimos (véase teoría de las cuerdas).

Véase también: cuaterniones; cuaterniones y rotación en el espacio; cuarta dimensión, quinta dimensión, multiverso (es.wikipedia.org/wiki/Diccionario_de_la_lengua_española) (Figura 4.5).

\section{DESARROLLO O CONSTRUCCIÓN DEL CONCEPTO}

En diseño industrial, particularmente hace referencia a las formas de representación técnica de los productos, alude a las dimensiones primarias o básicas de un producto, es decir, a las dimensiones máximas o las principales en los 3 ejes cartesianos $X, Y, Z$, lo que equivale al largo, ancho y alto; sin embargo, resulta necesario definir específicamente el producto a analizar, su configuración específica para saber con qué medidas puede ser caracterizado desde un punto de vista general, por ejemplo, una silla ¿qué 
DIMENSIONES... 160 CONCEPTOS CLAVE PARA LA FORMACIÓN DEL DISEÑADOR INDUSTRIAL • PARTE I

altura definiríamos como altura general, la altura total del respaldo ó la altura del asiento o ambas?, por lo tanto, resulta necesario analizar cada producto en particular así como su funcionamiento y configuración geométrica para definir sus correspondientes y suficientes dimensiones generales.

\section{USOS O ACEPCIONES (ACLARACIONES)}

Las dimensiones generales de un producto constituyen la información fundamental para cuantificar uno de sus costos directos.

Dentro de los planos de presentación es conveniente ubicar las dimensiones generales del producto.

\section{SINÓNIMOS}

Magnitudes principales, extensiones básicas, tamaños primarios.

\section{ANTÓNIMOS}

Dimensiones particulares, Tamaño específico, magnitud única.

\section{EJEMPLOS}

Máquina de vapor (Figura 4.6).

El texto Nueva manera de elevar el agua por medio del fuego, alude al trabajo publicado dos años antes por Thomas Savery.

Dimensiones generales de la máquina: $\mathrm{El}$ generador de vapor (A) o "retorta" — como lo llama Papin por su parecido con el instrumento químico de ese nombre - tiene un diámetro máximo de 20 ó 21" (508 ó 533,4 mm) y una altura de 26 " (66o $\mathrm{mm}$ ) con un volumen total en

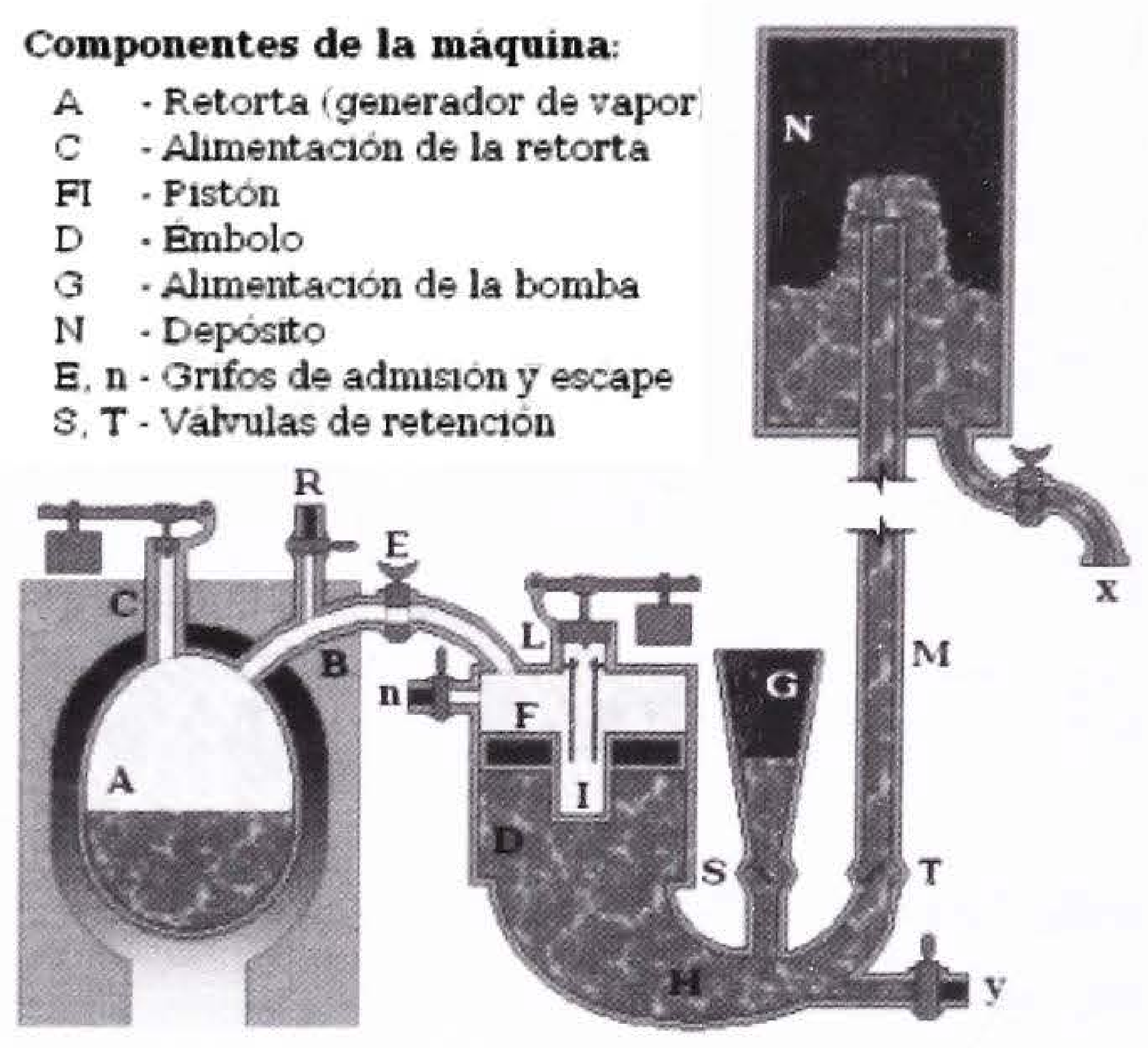

Figura 4.6. Componentes de una máquina de vapor.

torno a 150 litros. La retorta tiene un tubo (C) en la parte superior por el que se suministra el agua y que está durante la operación de la máquina cerrado por la válvula que permite, desplazando el peso, regular la presión del vapor en el interior de la retorta. Un segundo tubo comunica la retorta a través del grifo $\mathrm{E}$ con el cilindro.

El conjunto está encerrado en una obra de ladrillo que disminuye las pérdidas de calor. El aire caliente de la combustión se evacua por la parte superior del horno manteniendo caliente la retorta y el tubo (B) de alimentación de la bomba. La bomba tiene un diámetro de 20 " y una carrera de 16" (406 mm) con lo que en cada embolada se desplazan 200 libras de agua (unos 90 litros). A través de $\mathrm{G}$ se introduce el agua de alimentación.

El pistón (F) es hueco para que flote en el agua y en su centro tiene un hueco cilíndrico (I) 
cuyo propósito es habilitar el espacio necesario para poder introducir unas barras de acero al rojo que mantengan el vapor caliente (es.wikipedia.org/wiki/Diccionario_de_la_lengua_española).

\section{Especificaciones}

\section{Definición Diccionario RAE (DENOtACIÓN)}

Especificaciones. Acción y efecto de especificar. Explicar, declarar en particular.

En las áreas como la ingeniería o la manufactura el término especificación representa un documento técnico oficial que establece de forma clara todas las características, los materiales y los servicios necesarios para producir componentes destinados a la obtención de productos. Estos incluyen requerimientos para la conservación de dichos productos, su empaquetamiento, almacenaje y marcado, así como los procedimientos para determinar su obtención existosa y medir su calidad.

\section{DesarRollo o CONSTRUCCIÓN DEL CONCEPTO}

Para el diseño industrial el término especificaciones se refiere a caracteristicas detalladas de todas las partes y/o componentes que integran a los productos u objetos, como pueden ser las dimensiones, los materiales y sus respectivos procesos de transformación, incluyendo todas las características "especiales o particulares" que el producto o cualquiera de sus componentes pueda o deba poseer para cumplir de manera adecuada la función a que esté destinado satisfacer.

\section{USOS O ACEPCIONES (ACLARACIONES)}

Las especificaciones finales de un producto deben de estar referidas detalladamente en los planos de fabricación o producción.

Una corrida inicial de producción debe realizarse de acuerdo a las especificaciones definidas en el último nivel de revisión del diseño.

\section{SiNóNIMOS}

Detallar, ennumerar.

\section{ANTÓNIMOS}

Indefinido, no especifico.

\section{EJEMPLOS}

- Materiales: Acero 1010 al alto carbono, revenido.

- Dimensiones: $105.5 \mathrm{~mm}+-0.5 \mathrm{~mm}$.

- Acabado: Rectificado.

\section{Estándares de calidad}

\section{Definición Diccionario RAE (DENOTACIÓN)} Calidad. Es la manera de ser de una persona o cosa. Condición o requisito que se pone en un contrato. Estado de una persona, su naturaleza su edad y demás condiciones que se requieren para un cargo o dignidad. Nobleza de linaje. Importancia o gravedad de algo. Cualidades personales.

\section{DESARROLLO O CONSTRUCCIÓN DEL CONCEPTO}

La calidad es un término que en el diseño debe entenderse bajo el contexto de la mejora continua, de la innovación, por lo que resulta un 
objetivo inmutable en un proceso de esta naturaleza. Este concepto bajo la perspectiva de las organizaciones de la calidad significa "satisfacer los requisitos del cliente", lo cual implica requisitos de todo tipo, incluyendo los costos.

\section{USOS O ACEPCIONES (ACLARACIONES)}

En los productos más sofisticados tecnológicamente, los estándares de calidad que se requiere cumplir son los más altos, éstos pueden considerarse como indicadores del nivel de desarrollo tecnológico de un producto, así como de la empresa que los produce.

\section{SINÓNIMOS}

Normas de calidad, índices de calidad.

\section{ANTÓNIMO \\ Calidad aleatoria.}

\section{EJEMPLOS}

- Normas ISO 9000-2000.

- Normas ISO TS 16949.

- Normas ISO 14000.

\section{Estandarización}

\section{Definición Diccionario RAE (DENOTACIÓN)}

Estandarización. Sustantivo femenino que proviene del verbo transitivo estandarizar y significa tipificar, ajustar a un tipo, modelo o norma. La normalización o estandarización es la redacción de normas que se establecen para garantizar el acoplamiento de elementos construidos independientemente, así como garantizar el repuesto, en caso necesario, garantizar la calidad de los elementos fabricados, la seguridad de funcionamiento y trabajar con responsabilidad social.

\section{DESARROLLO O CONSTRUCCIÓN DEL CONCEPTO}

En el diseño industrial la estandarización es una herramienta básica para alcanzar la simplificación y, por lo mismo, la reducción del costo de cualquier producto o proceso. Su significado se entiende claramente como la unificación, como la reducción de la variedad tanto en los materiales como en los procesos, por ejemplo, si para el desarrollo de un producto usamos materiales con las mismas características, especificaciones o sea el mismo material, resulta más económico que el uso de distintos materiales y especificaciones, lo cual implicaría el uso de distintas máquinas o herramientas, o en último de los casos, realizar ajustes en las herramientas para adaptarlas a las variaciones requeridas por dichas especificaciones.

\section{USOS O ACEPCIONES (ACLARACIONES)}

La estandarización es un fenómeno que despersonaliza a los productos, se basa en datos estadísticos para la definición de las características antropométricas y ergonómicas. Con el establecimiento de un sistema estandarizado de producción es posible abatir los costos directos de producción.

\section{SiNóNIMOS}

Normalización, generalización. 


\section{ANTÓNIMOS}

Individualización, particularización.

\section{EJEMPLOS}

- Tallas de ropa, zapatos.

- Estándares antropométricos y ergonómicos.

- Comunicación de masas.

\section{Manufactura}

\section{Definición Diccionario RAE (DENOTACIÓN)}

Manufactura. Obra hecha a mano o con ayuda de máquina. Fábrica o lugar dónde se fabrica.

\section{DESARROLLO O CONSTRUCCIÓN DEL CONCEPTO}

La manufactura desde el punto de vista del diseño industrial abarca todos los procesos para fabricar un producto; también se considera que retoma todas las operaciones implicadas en un proceso más amplio y complejo conocido como "Cadena de suministro", en el cual la producción es solamente uno de los subprocesos que la integran; este proceso mayor comprende la fabricación, sea automatizada, manual o artesanal; así como la programación de todos los insumos requeridos para la fabricación de un producto final, y la distribución de los bienes fabricados, desarrollo conocido como "medio ambiente de la manufactura". Desde el campo disciplinario del diseño, habrá que considerar como parte del proceso de desarrollo de un producto, el aprovisionamiento de insumos y distribución de productos como variables o factores de importancia por su relación con la productividad y con el costo final del producto.

\section{USOS O ACEPCIONES (ACLARACIONES)}

Hoy en día, la globalización de la economía obliga a los diseñadores mexicanos a participar en el desarrollo de la competitividad, creando un medio ambiente de la manufactura similar o equivalente al de países desarrollados.

Una buena parte de los procesos de manufactura en México dentro de las compañías grandes, medianas y una pequeñas son competitivos dentro de los mercados globalizados, el aparente retraso de los mismos se debe a los procesos de gestión requeridos para llegar a dichos mercados.

\section{SINÓNIMOS}

Fabricación, producción.

\section{ANTÓNIMO}

No existe.

\section{EJEMPLOS}

- Medio ambiente de la manufactura automotriz.

- La manufactura de electrodomésticos en México, es una fortaleza competitiva a nivel mundial.

- Manufactura esbelta (Lean manufacturing).

\section{Materiales}

\section{DEFinición DicCionario RAE (DENOTACIÓN)} Materiales. Perteneciente o relativo a la materia. Propiedad material opuesto a lo espiritual. Opuesto a la forma. Grosero sin ingenio ni 
perspicacia. Ingrediente. Cualquiera de las materias que se precisan para la ejecución de una obra o el conjunto de ellas. Conjunto de máquinas, herramientas u objetos de cualquier clase preciso para el cumplimiento de un servicio o el ejercicio de una profesión.

\section{DESARROLLO O CONSTRUCCIÓN DEL CONCEPTO}

En diseño industrial se usan prácticamente todo el universo de materiales existentes para la fabricación de un producto, desde los tradicionales (madera, metales, cerámica, plásticos, vidrio, minerales y fibrosos) hasta los nuevos materiales llamados inteligentes, con sus respectivos procesos de transformación. Dado que es imposible conocer todos los materiales, resulta necesaria la especialización y/o la interdisciplina para explotar de la manera más adecuada las propiedades de los mismos, así como sus procesos de transformación, cuidando siempre la simplificación y los menores costos relativos a su aplicación en la solución de cualquier diseño.

Hoy en día también hay que considerar la variable de la sustentabilidad desde el punto de vista de las características y naturaleza de los materiales. Un diseño también debe ser el resultado, en este caso, optimizando la aplicación de los materiales que mejor funcionen y de mayor viabilidad, que sean reciclables y que no contaminen o puedan perjudicar al medio ambiente.

\section{USOS O ACEPCIONES (ACLARACIONES)}

Un área de desarrollo en México es la aplicación denuevos materiales comolos semiconductores.
Los materiales plásticos de ingeniería son fabricados en México bajo la licencia de firmas transnacionales, pero también se encuentran algunos producidos en otros países, por lo que es necesario importarlos.

\section{SINÓNIMOS}

Materias primas, insumos.

\begin{abstract}
ANTÓNIMO
Antimateria.

\section{EJEMPLOS}

El consumo de los materiales plásticos aumentó a partir de los últimos 20 años del siglo XX, sustituyendo a la mayor parte de los materiales convencionales. Los materiales fibrosos comprenden las fibras naturales, las fibras sintéticas y la madera.
\end{abstract}

\section{Partes}

\section{Definición Diccionario RAE (DENOTACIÓN)}

Partes. Porción indeterminada de un todo. Cantidad o porción determinada de un agregado numeroso. Porción que se le da a uno en repartimiento o cuota que le corresponde en cualquiera comunidad o distribución. Sitio o lugar. Dependencia, sección, subdivisión. Cada una de la divisiones principales y que comprende otras menores de una obra científica y literaria. En ciertos géneros literarios obra entera que se relaciona con otra $u$ otras que también se llaman partes. Cada uno de los ejércitos, facciones, 
sectas que se oponen o contienden. Cada uno de los que contratan entre sí o tienen participación en el mismo negocio. Cada una de las personas o grupos de ellas que disputan o dialogan. Cada una de las palabras de que consta un renglón. Lado a que uno se inclina o se opone en cuestión o pendencia. Papel representado por un actor en una obra dramática o cinematográfica. Cada uno de los actores o cantantes que forman una compañía. Litigante. Despacho o cédula que se entregaba a los correos que iban de posta, en que se daba noticia del punto adonde se encaminaban, del día y la hora de partida y por orden de quien iban.

\section{DESARRollo o CONSTRUCCIÓN DEL CONCEPTO}

En el diseño industrial puede considerarse de acuerdo a un convencionalismo que establece una jerarquía en la estructura completa de un producto, como un sistema; esta jerarquización obedecería al siguiente orden, a partir de ver al producto como un todo: el producto equivaldría a un sistema y estaría compuesto por subsistemas o componentes, y elementos o partes, o bien a la inversa, es decir, que los elementos integrarían a las partes, las partes a los componentes, los componentes a los subsistemas y los subsistemas a los sistemas, por lo que este concepto es relativo a un orden jerarquizado de la integración de un producto.

\section{USOS O ACEPCIONES (ACLARACIONES)}

Las partes de un equipo de cómputo son el monitor, el teclado y el procesador.

\section{SiNÓNIMO}

Pieza.

\section{ANTÓNIMO}

No existe.

\section{EJEMPLOS}

- Sistema-Producto.

- Subsistema-Componentes.

- Elemento-Partes.

\section{Planos de producción}

\section{Definición Diccionario RAE (DENOtACión)}

Producción (véase definición p. 149).

Plano. Para la topografía significa la representación gráfica de un terreno o una planta de un campamento, plaza, etc..., en una superficie mediante procedimientos técnicos. Para la geometría se menciona el término de "Plano coordenado" haciendo alusión a los ejes cartesianos, se usa para definirlos como cada uno de los tres planos que se cortan en un punto, y con los cuales se determina la posición de los demás puntos del espacio. "Plano geométrico", es un término usado en perspectiva, superficie plana paralela al horizonte, donde se proyectan los objetos para construir su perspectiva. También encontramos en términos similares las definiciones de plano horizontal y vertical que se refieren a los definidos por los ejes cartesianos anteriormente mencionados. 


\section{DESARROLLO O CONSTRUCCIÓN DEL CONCEPTO}

En el diseño industrial los "planos de producción" se refieren a documentos que además de la representación en proyecciones ortogonales del producto diseñado a todo detalle, también se plasman todas las especificaciones que se requieren para que el producto pueda ser fabricado de manera "iterativa" o repetitiva, independientemente de que los procesos de fabricación no sean del tipo industrial. Al contener las especificaciones del producto estos planos integran la información básica, hoy en día conocida como Know how tecnológico, de ahí su importancia. Cabe mencionar que respecto a los estándares de dibujo, su normalización depende en gran medida de la aplicación especifica del plano, dentro del respectivo proceso de producción y de la empresa, o hasta de la localización geográfica de dicha empresa, lo que significa que "no son universales" o definitivos, por ello es vital que contengan toda la información necesaria y que ésta sea totalmente comprensible y confiable para la reproducción del producto.

\section{USOS O ACEPCIONES (ACLARACIONES)}

$\mathrm{El}$ alcance de un proyecto de diseño puede establecerse hasta la realización de los planos de producción con todas las especificaciones del producto para su lanzamiento al mercado. Dentro de los planos de producción de un molde de inyección es muy importante incluir los acabados superficiales y los índices de contracción de los materiales.

\section{SINÓNIMO}

Planos de taller.

\section{ANTÓNIMO}

No existe.

\section{Procesos de fabricación}

\section{DEFINICIÓN DicCionaRio RAE (DENOTACIÓN)}

Proceso significa progreso. Transcurso del tiempo. Conjunto de fases sucesivas de un fenómeno natural o de una operación artificial.

Fabricación es la acción y efecto de fabricar.

\section{DESARROLLO O CONSTRUCCIÓN DEL CONCEPTO} Expresión compuesta de uso común en el diseño dado su significado; es aplicado a lo largo del desarrollo de cualquier proyecto ya que es uno de los factores a considerar. Resulta pertinente comentar que su difusión responde a la explosiva evolución de las tecnologías de la información aplicadas a la producción, presentes en prácticamente todas las tecnologías de transformación, al grado de que es posible digitalizar cualquier proceso de producción o de fabricación, sustituir en geometría, tiempo, precisión y acabados la mano de obra directa (humana), sin embargo no debemos descartar la definición y especificación de los procesos convencionales.

\section{USOS O ACEPCIONES (ACLARACIONES)}

Es muy importante visualizar y definir los procesos de fabricación disponibles en una empresa 
para no incrementar de manera innecesaria los costos de fabricación de un nuevo producto.

\section{SiNóNIMOS}

Proceso de elaboración, proceso de producción.

\section{ANTÓNIMO}

No existe.

\section{EJEMPLOS}

El costo de los procesos de fabricación especificados es determinante para el cálculo del costo final de cualquier producto.

Los procesos de fabricación de uso intensivo de mano de obra pueden ser calculados y definidos con base en estándares.

\section{Producto industrializado}

\section{Definición Diccionario RAE (DENOTACIÓN)}

Producto (véase definición p. 155).

Industrializado, proviene del verbo industrializar que significa hacer algo que sea objeto de industria o elaboración. De este verbo se deriva el término de "Industrialización".

\section{DesarRollo o construcción del concepto}

Término base del diseño, la característica básica de un producto o de un proyecto de diseño industrial; su campo de acción se refiere solamente a la producción de tipo industrial, que a su vez se asocia directamente a un tipo de producción apoyada por medios industriales o máquinas, cuando la realidad es que si analizamos las definiciones del diccionario ninguna nos indica de manera clara o evidente del tipo de producción involucrado dentro de los parámetros de este término, resulta oportuno pues hacer una reflexión aparte acerca de cómo interpretar su significado.

\section{USOS O ACEPCIONES (ACLARACIONES)}

Existen productos industrializados muy sofisticados que requieren de un uso intensivo de la mano de obra directa, sobre todo para operaciones de ensamble.

Los productos industrializados son los que con más frecuencia generan un mayor valor agregado.

\section{SINÓNIMOS}

Productos fabricados, productos manufacturados.

\section{ANTÓNIMOS}

Productos hechos a mano, productos artesanales.

\section{EJEMPLOS}

- Electrodomésticos.

- Equipos electrónicos.

- Aviones. 


\section{Sistema normalizado de representación e interpretación}

\section{Definición Diccionario RAE (DENOTACIÓN)}

Sistema. Conjunto de reglas o principios enlazados entre sí. Conjunto de cosas ordenadamente relacionadas entre sí o constituyen en cierto modo una unidad.

Normalizado, proviene del verbo normalizar que significa regularizar o poner en buen orden lo que no estaba.

Representación, es la acción o efecto de representar o representarse. Función de teatro. Autoridad, dignidad, carácter de la persona. Imagen o idea que sustituye a la realidad. Súplica apoyada en razones o comprobantes que se dirige a un superior. Imagen o idea que sustituye la realidad. Súplica apoyada en razones o comprobantes que se dirige a un superior. Conjunto de personas que representan a una colectividad, entidad o corporación. Derecho de una persona a ocupar para la sucesión en una herencia, el lugar de otra persona.

Interpretación. Que se describe como la acción y efecto de interpretar, verbo que significa aclarar o declarar el sentido de algo, y especialmente el de textos poco inteligibles. Traducir de una lengua a otra. Comprender o tomar en buen o mal sentido una acción o palabra. Atribuir una acción a determinado fin o causa. Entender o expresar bien o mal el asunto o materia de que se trata. Dícese en particular de los actores o los artistas en general.

\section{DESARROLLO O CONSTRUCCIÓN DEL CONCEPTO}

Se emplea en diseño industrial para referirse al sistema acordado de comunicación del producto diseñado para su más fiel reproducción, cumpliendo con las normas adecuadas o acordadas; lo importante es el acuerdo previo para la aplicación del sistema a utilizar de manera regular como principio de comunicación.

Es importante señalar que los principios básico de normalización de la representación e interpretación se encuentran reflejados por todos los estándares existentes, que tienen como objetivo comunicar de manera concertada e inequívoca todas las cualidades y/o características de un producto para su reproducción, hoy en día resulta muy común el uso de las herramientas de la informática para este fin, por lo que no resulta extraño que los mismosprogramas aplicados para el modelado tridimensional existentes tengan equivalencias o sean compatibles entre sí.

\section{USOS O ACEPCIONES (ACLARACIONES)}

Como estrategia fundamental para el desarrollo tecnológico se debe establecer o definir un sistema estandarizado de representación e interpretación. Existen básicamente dos sistemas normalizados de representación e interpretación para elaborar los planos de un producto: el americano y el europeo.

\section{SiNóNIMOS}

Estándares de fabricación, estándares de calidad.

\section{ANTÓNIMO}

No existe. 


\section{EJEMPLOS}

- Sistema ISO.

- Sistema NOM (Norma Oficial Mexicana).

\section{Tolerancias geométricas y dimensionales}

\section{DEFinición DicCionario RAE (DENOTACIÓN)}

Tolerancia, acción y efecto de tolerar, también se trata de una palabra con varios significados como el respeto a las opiniones, usos y prácticas de los demás. Inmunidad política que se concede al que profesa una religión que no es la oficial. Máxima diferencia que se tolera o admite entre el valor real o efectivo en las características físicas y químicas de un material, pieza o producto.

Geométrica, perteneciente a la geometría. Muy exacto.

Dimensional, perteneciente a una dimensión, que a su vez se refiere a la longitud, extensión o volumen de una línea, superficie o cuerpo, respectivamente.

\section{DESARROLLO O CONSTRUCCIÓN DEL CONCEPTO}

Término poco conocido en diseño, pero esencial para la aplicación a detalle de las diversas tecnologías de transformación, con métodos matemáticos para la definición de las características de las medidas o dimensiones de los productos o de los medios de producción definidos o especificados para la reproducción de los mismos; a veces, se presupone de manera equivocada que este tipo de actividades corresponden sólo al campo disciplinario de la ingeniería, sin embargo, es indispensable para el diseñador, por lo menos poseer la capacidad de visualizar de qué manera afectan estos factores al producto de diseño.

Por ejemplo, la obvia diferencia que existe entre un plano de un electrodoméstico con el de una silla de plástico, así mismo, existe una gran diferencia entre el plano de un mueble proyectado para ser fabricado en madera, que uno que va a ser producido en metal u otro que será moldeado en algún material plástico; también encontramos que los planos para la producción con base en los distintos materiales tienen diferencias ya que en algunos será requisito aplicar los principios de las tolerancias geométricas y dimensionales, sobre todo cuando hablamos de los planos de producción de partes que requieren de gran precisión, como los moldeados por inyección o los troquelados metálicos.

\section{USOS O ACEPCIONES (ACLARACIONES)}

Los tolerancias geométricas y dimensionales son estándares aplicados para controlar la calidad de los productos que requieren un alto grado de precisión ya sea porque son partes o componentes que van a integrar un producto ensamblado; y para la fabricación de herramentales requeridos para los procesos de fabricación continua como los moldes de inyección y las matrices o troqueles.

\section{SINÓNIMO}

Especificaciones geométricas y dimensionales, requerimientos geométricos y dimensionales. 


\section{ANTónimo}

Sin tolerancias geométricas y dimensionales, sin normalización, no normalizado.

\section{EJEMPLOS}

- Moldes de inyección.

- Dados para extrusión.

- Engranes helicoidales.

- Troqueles, matricería.

\section{Bibliografía}

Ejercicio profesional del diseño industrial. Un acercamiento al análisis de algunas de las especialidades más dinámicas en México. México, UAM Azcapotzalco, 2003.

LEVITT, Theodore (1981), "El ciclo de vida del producto: gran oportunidad de marketing", Harvard-Deusto Business Review ( $2^{\circ}$ trimestre), pp. 5-28.

RICARD, André (1983), Diseño ¿porqué?, Barcelona: Gustavo Gili (Punto y línea).

Rodríguez, Manuel y Torres, Raúl M. (2009), El diseño en el futuro de México. Visiones analiticas y prospectivas, México, UAM Cuajimalpa.

TriLogio (2006), Vision Lean/Lean tek Philosophy,

Francia: Iris Impression S.A.

es.wikipedia.org/wiki/Diccionario_de_la_ lengua_española. 